ABDI: Jurnal Pengabdian dan Pemberdayaan Masyarakat ISSN: 2656-369X (Print), 2684-8570 (Online)

Volume 2 No. 1, Juni 2020

http://abdi.ppj.unp.ac.id/index.php/abdi

Email: abdi@ppj.unp.ac.id

DOI: https://doi.org/10.24036/abdi.v2il.33

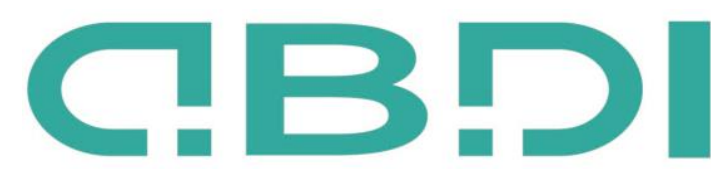

ABDI: JURNAL PENGABDIAN DAN PEMBERDAYAAN MASYARAKAT

\title{
Pengembangan Kompetensi Guru dalam Pembelajaran Berbasis Budaya: Culturally Responsive Transformative Teaching (CRTT)
}

\author{
Yuli Rahmawati ${ }^{1}$, Achmad Ridwan', Mega Ayu Agustin ${ }^{3}$ \\ ${ }^{1,2,3}$ Program Studi Pendidikan Kimia, Universitas Negeri Jakarta \\ E-mail: yrahmawati@unj.ac.id
}

\begin{abstract}
Abstrak
Artikel ini merupakan hasil dari kegiatan pengabdian masyarakat yang bertujuan untuk mengembangkan kompetensi guru dalam pembelajaran berbasis budaya yaitu Culturally Responsive Transformative Teaching (CRTT). Workshop ini dapat menjadi salah satu solusi yang dapat membantu guru dalam menjawab tantangan yang diberikan oleh kurikulum 2013, terkait pengembangan nilai-nilai karakter dan budaya. Pelaksanan pengabdian masyarakat dilakukan di dua sekolah islam terpadu di Banten yaitu di Sekolah Islam Terpadu Bina Insani dan SDIT Ibadurrahman. Jumlah guru yang terlibat sebanyak 58 guru, Sekolah Islam Terpadu Bina Insani (37 orang) dan SDIT Ibadurrahman sebanyak (21 orang). Kegiatan workshop dilaksanakan dalam empat tahap, yaitu pemberian framework, integrasi budaya dalam mata pelajaran yang diampu, perancangan pembelajaran, dan presentasi hasil. Model pembelajaran dengan pendekatan CRTT diterapkan dengan lima tahapan yaitu self identification, cultural understanding, collaboration, critical reflections, transformative construction. Pengumpulan data dilakukan dengan wawancara informal dan reflektif jurnal. Analisis data dilakukan dengan analisis tema dan dipresentasikan sesuai pendapat guru secara deskripsi dan naratif. Hasil kegiatan menunjukkan guru dapat melakukan integrasi budaya Banten dalam berbagai mata pelajaran serta merencanakan pembelajaran. Di samping itu, kegiatan workhop telah mengembangkan keterampilan berpikir kritis, bekerja sama, dan rasa ingin tahu. Model pembelajaran dapat membantu guru dalam pengembangan identitas budaya dan karakter yang sejalan dengan kurikulum.
\end{abstract}

Kata kunci: Culturally Responsive Transformative Teaching (CRTT), Kompetensi guru, Integrasi budaya, Pembelajaran berbasis budaya

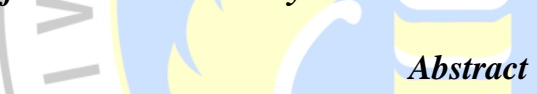

This article portrays the community services aimed for developing teacher competencies in culturally based teaching through Cultural Responsive Transformative Teaching (CRTT) model. The workshop has aimed to develop teachers' competences in conducting innovative teaching model in relation to 2013 curriculum through the basic principles of students' characteristics and cultural identity. The research was conducted in two integrated Islamic schools in Banten, namely the Integrated Islamic School of Bina Insani and SDIT Ibadurrahman. There were 58 teachers with Bina Insani Integrated Islamic School (37 teachers) and in SDIT Ibadurrahman (21 teachers). The workshop conducted through the usteps of delivering the framework, creating cultural integration in the different subjects, developing lesson plan, and presenting the results. The CRTT learning model has steps of self-identification, cultural understanding, collaboration, critical reflection, transformative construction. Data was collected by informal interviews and reflective journals. The data analysis was conducted through analyzing theme then presented through teachers'voices and narrative. The result showed teachers can integrated Banten cultures in various subjects and planning the lesson. In addition, the workshop has stimulated their critical thinking, collaboration, and couriousity. The learning model could help teachers in developing students' cultural identity and characters, as relevant to the curriculum.

Keywords: Culturally Responsive Transformative Teaching (CRTT), Teacher competences, Cultural integration, Cultural based teaching

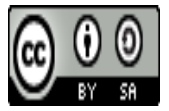

Received: 6 Desember 2019

Revised: 27 Februari 2020

Available Online: 28 Februari 2020 


\section{Pendahuluan}

Pendidikan tidak hanya bertujuan untuk meningkatkan kompetensi peserta didik pada konsep-konsep bidang ilmu (aspek pengetahuan), namun juga untuk menghasilkan generasi muda yang memiliki kemampuan menjadi agent of change, berkarakter, dan berbudaya dalam menghadapi tantangan masa depan. Pendidikan karakter dan budaya telah menjadi isu penting dalam kurikulum di berbagai level, khususnya mengembangkan kompetensi peserta didik untuk mengatasi permasalahan dalam kehidupan sehari-hari dan melaksanakan peranannya di masa yang akan datang. (Chang, F, 2006). Pendidikan seharusnya menghasilkan generasi yang profesional serta warga negara yang berkualitas, dimana tidak hanya generasi yang memiliki pengetahuan, namun juga kemauan untuk terus belajar serta kemampuan personal dan nilai-nilai yang dimiliki. (Arthur, J. \& Wilson, K., 2010) Selanjutnya secara khusus, sekolah berperan penting dalam membangun karakter dan budaya peserta didik, khususnya menghadapi permasalahan di masyarakat yang semakin kompleks serta multikultur. (Hutcheon, P.D., 1999). Dengan demikian pengembangan generasi masa depan yang holistik dalam hal karakter, budaya dan kompetensi masa depan menjadi bagian penting dalam proses pendidikan.

Bangsa Indonesia merupakan bangsa yang majemuk dengan kekhasan suku dan budaya dengan beragam latar belakang yang berbeda. Indonesia memiliki lebih dari 1.300 suku bangsa dengan jenis yang beragam, dengan jumlah populasi setiap suku bangsa juga sangat bervariasi, suku jawa menjadi suku yang paling mendominasi (Badan Pusat Statistik, 2010). Namun era globalisasi telah berdampak kepada lunturnya kebudayaan dan identitas budaya di Indonesia Mubah. A.S., 2011). Arus globalisasi berdampak pada hubungan seseorang terhadap lingkungan dan budayanya, termasuk bahaya budaya homogenisasi dan pola dominasi budaya barat (Otasevic, K., 2013). Hal ini juga berdampak kepada generasi muda yaitu lunturnya nilai-nilai nasionalisme (Hassan Suryono, 2007). Pelestarian budaya sebagai antisipasi dampak globalisasi melalui berbagai aspek perlu terus dikembangkan.

Salah satu aspek yang dapat mengembangkan identitas budaya sebagai sarana untuk melestarikan budaya, khususnya pada generasi muda adalah melalui pendidikan. Tantangan pendidikan pada era globalisasi telah mendorong pemerintah mengembangkan berbagai upaya untuk mengembangkan identitas budaya peserta didik (Rahmawati, Y. \& Taylor, P.C., 2015). Salah satunya pada Peraturan Menteri Pendidikan dan Kebudayaan berkaitan dengan implementasi kurikulum 2013 melalui pelajaran muatan lokal untuk dapat mengenalkan peserta didik dengan lingkungan sosial, alam dan budayanya.

Pendidikan karakter yang menjadi landasan kurikulum 2013 memberikan kesempatan untuk membawa unsur identitas budaya dan pembentukan karakter di dalam proses pembelajaran. Pendidikan dapat menjadi unsur penting dalam upaya melestarikan budaya bangsa, karena tanpa adanya keterlibatan pendidikan, budaya lokal akan dihilangkan oleh modernitas masyarakat (Arifah, 2014).

Pendidikan karakter pada peserta didik merupakan pendidikan nilai-nilai dasar dan tingkah laku Arthur, J., 2009). Pendidikan seharusnya menghasilkan pekerja yang professional serta warga negara yang berkualitas, yaitu tidak hanya generasi yang memiliki pengetahuan, namun juga kemauan untuk terus belajar serta kemampuan personal dan nilai-nilai yang dimiliki (Arthur, J. \& Wilson, K., 2010). Sehingga sekolah berperan penting dalam membangun karakter dan budaya peserta didik, khususnya menghadapi permasalahan di masyarakat yang semakin kompleks serta semakin multikultur (Hutcheon, P.D, 1999).

Implementasi pendidikan karakter dalam kurikulum 2013 tentunya memiliki tantangan, dalam steakholder pendidikan terutama guru sebagai objek vital dalam pendidikan. Guru sebagai tenaga professional memiliki tugas utama mendidik, mengajar, membimbing, mengarahkan, melatih, menilai, dan mengevaluasi peserta didik (Undang-undang Nomor 20 tahun 2003). Untuk menunjang profesinya, sebagaimana yang diamanatkan dalam Permeneg PAN dan RB Nomor 16 tahun 2009 (Daniel, S, 2007) tentang jabatan fungsional guru dan angka kreditnya, seorang guru juga dituntut memiliki kewajiban, dan bertanggungjawab untuk meningkatkan dan mengembangkan kualifikasi akademik dan kompetensi secara berkelanjutan sejalan dengan perkembangan ilmu pengetahuan, teknologi, dan seni. 
Yuli Rahmawati, Achmad Ridwan, Mega Ayu Agsutin Pengembangan Kompetensi Guru dalam Pembelajaran Berbasis Budaya: Culturally Responsive Transformative Teaching (CRTT)

Dalam memenuhi kompetensi professionalnya, terdapat 5 (lima) hal yang harus dimiliki guru, yaitu: 1) menguasai materi, struktur, konsep dan pola pikir keilmuan yang mendukung mata pelajaran yang diampu, 2) menguasai kompetensi dasar mata pelajaran yang diampu, 3) mengembangkan materi pelajaran yang diampu secara kreatif dalam proses pembelajaran, 4) mengembangkan keprofesian secara berkelanjutan dengan melakukan tindakan reflektif, dan 5) memanfaatkan teknologi informasi dan komunikasi untuk berkomunikasi dan mengembangkan diri (Peraturan Menteri Pendidikan dan Kebudayaan Republik Indonesia Nomor 103 Tahun 2013). Berdasarkan kompetensi professional tersebut salah satu hal penting yang harus guru lakukan adalah mengembangkan materi pembelajaran yang kreatif dalam proses pembelajaran. Hal tersebut diperkuat dengan amanah kurikulum 2013 bahwa pembelajaran yang dilaksanakan, harus berbasis aktivitas dengan karakteristik: 1) interaktif dan inspiratif, 2)menyenangkan, menantang, dan memotivasi peserta didik untuk berpartisipasi aktif, 3) kontekstual dan kolaboratif, 4) memberikan ruang yang cukup bagi prakarsa, kreativitas, dan kemandirian peserta didik, dan 5) sesuai dengan bakat, minat, kemampuan, dan perkembangan fisik serta psikologis peserta didik. Kurikulum 2013 menuntut guru untuk berkontribusi bukan hanya dalam materi atau konsep pelajaran tapi juga karakter dari peserta didik, oleh karena itu pembekalan guru terhadap suatu model pembelajaran inovatif yang dapat digunakan untuk membuat pembelajaran yang lebih bermakna dan mengembangkan karakter peserta didik sangat diperlukan.

Pembelajaran berbasis budaya telah dikembangkan untuk menciptakan pembelajaran bermakna adalah dengan mengaitkan pembelajaran dengan latar belakang budaya peserta didik (Aikenhead, G, 2000). Pendidik harus menyadari bahwa terdapat kaitan erat antara budaya dengan cara berpikir peserta didik (Gay, G, 2000). Integrasi latar belakang budaya peserta didik merupakan upaya untuk mendekatkan peserta didik dengan konteks pembelajaran dan kesadaran peserta didik terhadap identitas budayanya (Gay, G, 2000). Salah satu model pembelajaran yang dapat diterapkan dalam pembelajaran guna menanamkan nilai-nilai karakter dan budaya adalah CRTT (Culturally Responsive Transformative Teaching) yang merupakan pendekatan pembelajaran yang menghubungkan latar belakang, pengalaman, gaya belajar, dan karakteristik untuk kepentingan akademik (Rahmawati, Y., \& Ridwan, A., 2019).

Pendekatan CRTT yang dikembangkan dari konsep CRT (Culturally Responsive Teaching) juga memberikan cara peserta didik untuk memperoleh pengetahuan baru melalui lingkungan sekitar dan latar belakangnya (Gay, G, 2000). Sehingga, penerapan pendekatan ini akan menekankan pada berbagai teknik yang terkait dengan integrasi budaya dan latar belakang, serta karakteristik guru.

Pencapaian kompetensi pada kurikulum 2013 ini tidak terlepas dari strategi, model, teknik serta metode yang sesuai dengan karakteristik peserta didik, serta tidak terlepas dengan karakteristik mata pelajatan masing- masing. Penelitian terkait budaya telah dilakukan dalam pembelajaran di Indonesia yang terkait dengan pendidikan budaya berbasis budaya lokal Sarwanto, \& Budiharti, R., 2013). Serta dampaknya terhadap literasi sains, minat dan prestasi belajar peserta didik, dan hasil belajar, serta entrepreneurship.

Workshop dilaksanakan di Provinsi Banten. Provinsi ini pada awalnya merupakan bagian dari Provinsi Jawa Barat, namun dipisahkan sejak tahun 2000, dengan keputusan Undang-Undang Nomor 23 Tahun 2000. Pusat pemerintahannya berada di Kota Serang. Banten adalah sebuah provinsi di Tatar Pasundan, serta wilayah paling barat di Pulau Jawa, Indonesia. Provinsi ini pernah menjadi bagian dari Provinsi Jawa Barat, namun menjadi wilayah pemekaran sejak tahun 2000, dengan keputusan Undang-Undang Nomor 23 Tahun 2000. Pusat pemerintahannya berada di Kota Serang.

Sebagian besar anggota masyarakat Banten memeluk agama Islam dengan semangat religius yang tinggi, tetapi pemeluk agama lain dapat hidup berdampingan dengan damai. Potensi, dan kekhasan budaya masyarakat Banten, antara lain seni bela diri Pencak silat, Debus, Rudad, Umbruk, Tari Saman, Tari Topeng, Tari Cokek, Dog-dog, Palingtung, dan Lojor. Di samping itu juga terdapat peninggalan warisan leluhur antara lain Masjid Agung Banten Lama, Makam Keramat Panjang, dan masih banyak peninggalan lainnya.

Di Provinsi Banten terdapat Suku Baduy. Suku Baduy Dalam merupakan suku asli Sunda Banten yang masih menjaga tradisi antimodernisasi, baik cara berpakaian maupun pola hidup

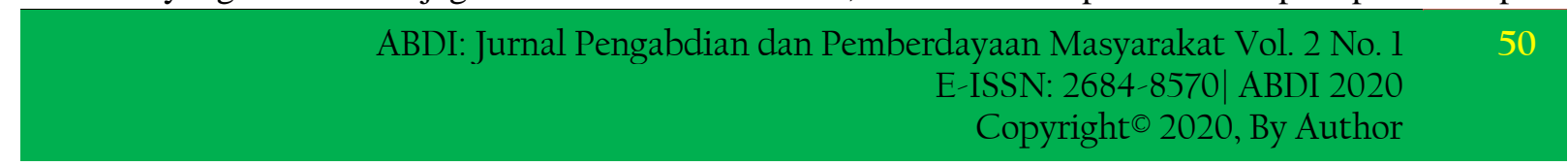


lainnya. Suku Baduy-Rawayan tinggal di kawasan Cagar Budaya Pegunungan Kendeng seluas 5.101,85 hektare di daerah Kanekes, Kecamatan Leuwidamar, Kabupaten Lebak. Perkampungan masyarakat Baduy umumnya terletak di daerah aliran Sungai Ciujung di Pegunungan Kendeng. Daerah ini dikenal sebagai wilayah tanah titipan dari nenek moyang, yang harus dipelihara, dan dijaga baik-baik, tidak boleh dirusak. Sehingga workshop ini diharapkan dapat membantu pelestarian budaya banten melalui pendidikan.

Selanjutnya, workshop pada kegiatan pengabdian masyarakat ini diharapkan dapat menginisiasi guru untuk merancang pembelajaran di kelas yang lebih bermakna dan melibatkan peserta didik secara aktif dalam pembelajaran. Hal ini juga didukung oleh penelitian sebelumnya yang menerapkan pembelajaran berbasis budaya, hasil menunjukkan bahwa peserta didik lebih terlibat dalam pembelajaran ketika hal itu berkaitan dengan kehidupan sehari-hari mereka (Rahmawati, Y., Nurbaity, \& Marheni, 2014).

Workshop untuk mengembangkan kompetensi guru dalam pembelajaran dengan menggunakan CRTT ini dapat menjadi salah satu solusi yang dapat membantu guru dalam menjawab tantangan yang diberikan oleh kurikulum 2013, dimana dengan pendekatan pembelajaran model CRTT dapat membuat guru lebih berinovasi dalam pembelajaran di kelas dan menerapkan nilai-nilai karakter budaya Indonesia.

\section{Metode Pelaksanaan}

Kegiatan pengabdian masyarakat ini bertujuan untuk memberikan Workshop kepada guru terkait penggunaan model pembelajaran CRTT dalam pembelajaran bagi guru-guru dalam upaya mengembangkan kompetensi guru. Workshop dilaksanakan di Sekolah Islam Terpadu Bina Insani dan SDIT Ibadurrahman. Jumlah guru sebanyak 58 orang, dengan masing-masing Sekolah Islam Terpadu Bina Insani sebanyak 37 orang dan di SDIT Ibadurrahman sebanyak 21 orang. Pada pelatihan ini guru-guru diberikan kegiatan berupa workshop. dalam empat tahap, yaitu pemberian framework, integrasi budaya dalam mata pelajaran yang diampu, perancangan pembelajaran, dan presentasi hasil. Pengambilan data dilakukan dengan wawancara informal dan reflektif jurnal. Penerapan model pembelajaran CRTT ini dilaksanakan dengan mengaitkan karakteristik guru dan kebudayaan dijabarkan pada prinsip-prinsip yang dikembangkan dalam model pembelajaran yang digunakan, yang akan dijelaskan dibawah ini :

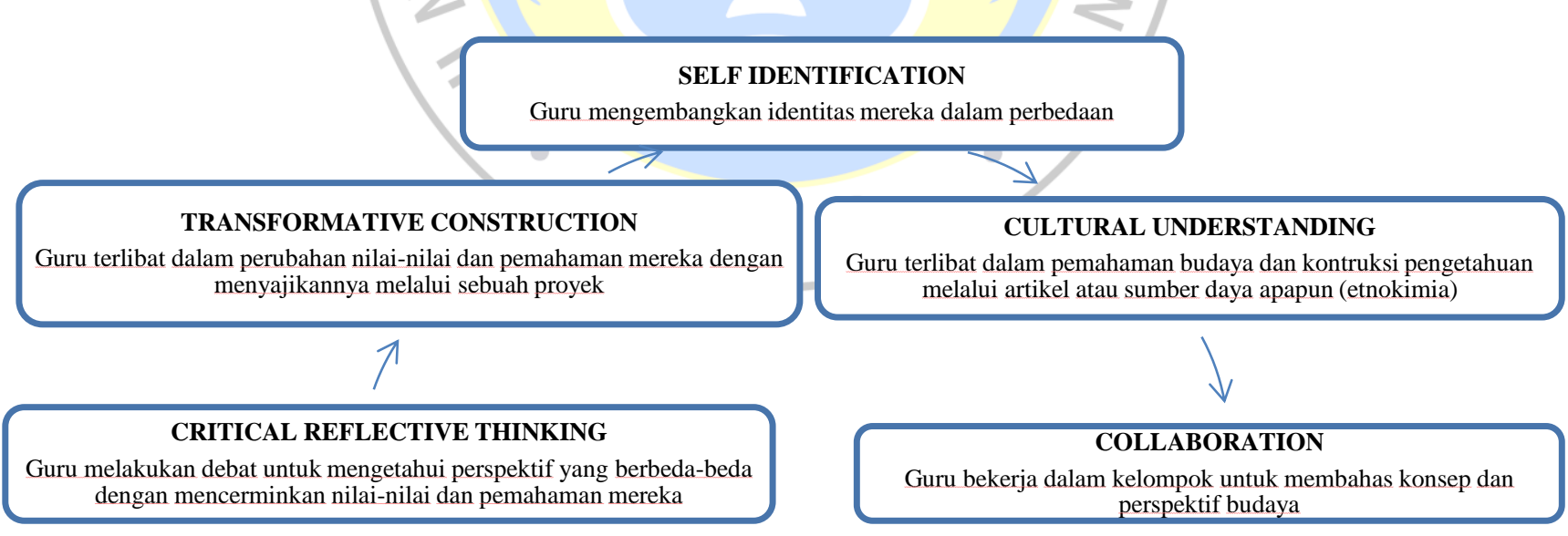

\section{Gambar 1. Model pembelajaran CRTT}

Pengembangan model CRTT terdiri dari 5 tahap, yaitu self identification (identitas diri), cultural understanding (pemahaman budaya), collaboration (kolaborasi), critical reflections (berpikir refleksi kritis), transformative construction (konstruksi transformatif) yang ditunjukkan pada gambar 1 (Rahmawati, Y., \& Ridwan, A, 2019). 


\section{Hasil dan Pembahasan}

Workshop pengembangan kompetensi guru dalam model pembelajaran ini, berdampak terhadap kompetensi guru dalam hal kreativitas dalam integrasi konten budaya, berpikir kritis, bekerjasama, dan rasa ingin tahu.

\subsection{Kreativitas Integrasi Budaya dalam Mata Pelajaran}

Model pembelajaran CRTT memfasilitasi kesadaran budaya dan sosial guru. Guru menyadari bahwa inovasi ini dapat membangkitkan motivasi peserta didik belajar hal ini sejalan pengajaran dan pembelajaran yang efektif terjadi dalam konteks yang berpusat pada budaya yang menjadi potensi keberhasilan belajar peserta didik (Semali, L., 2013). Hampir setiap aspek pada model pembelajaran CRTT dapat mendukung terbentuknya kesadaran sosial budaya yang mencakup empati komunikasi, bertanggung jawab, disiplin, dan kepedulian sosial. "Budaya Banten yang beragam ternyata dapat dikaitkan dalam berbagai mata pelajaran". (Refleksi guru SDIT 2).

Salah satu ciri pendekatan CRTT yaitu memperhatikan latar belakang budaya yang dapat menstimulasi munculnya kesadaran identitas budaya. Gambar 2 dan 3 merupakan poster yang dibuat oleh guru, dalam poster tersebut guru mengembangkan kreativitasnya dan mengintegrasikan budaya ke dalam pelajaran, yaitu matematika dalam konsep bangun datar, PJOK dalam konsep tradisi suku Baduy, IPS dalam konsep pakaian adat, dan IPA dalam konsep lingkungan.

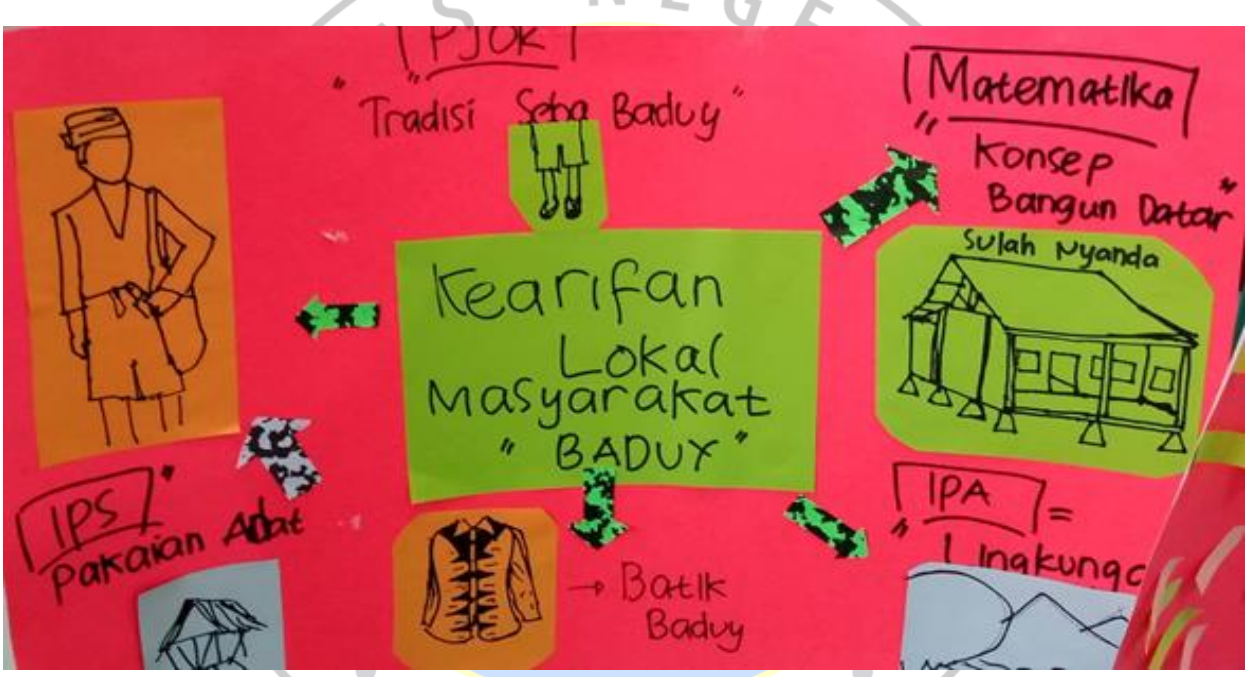

Gambar 2. Konsep Matematika, PJOK, IPS, dan IPA pada Budaya Baduy

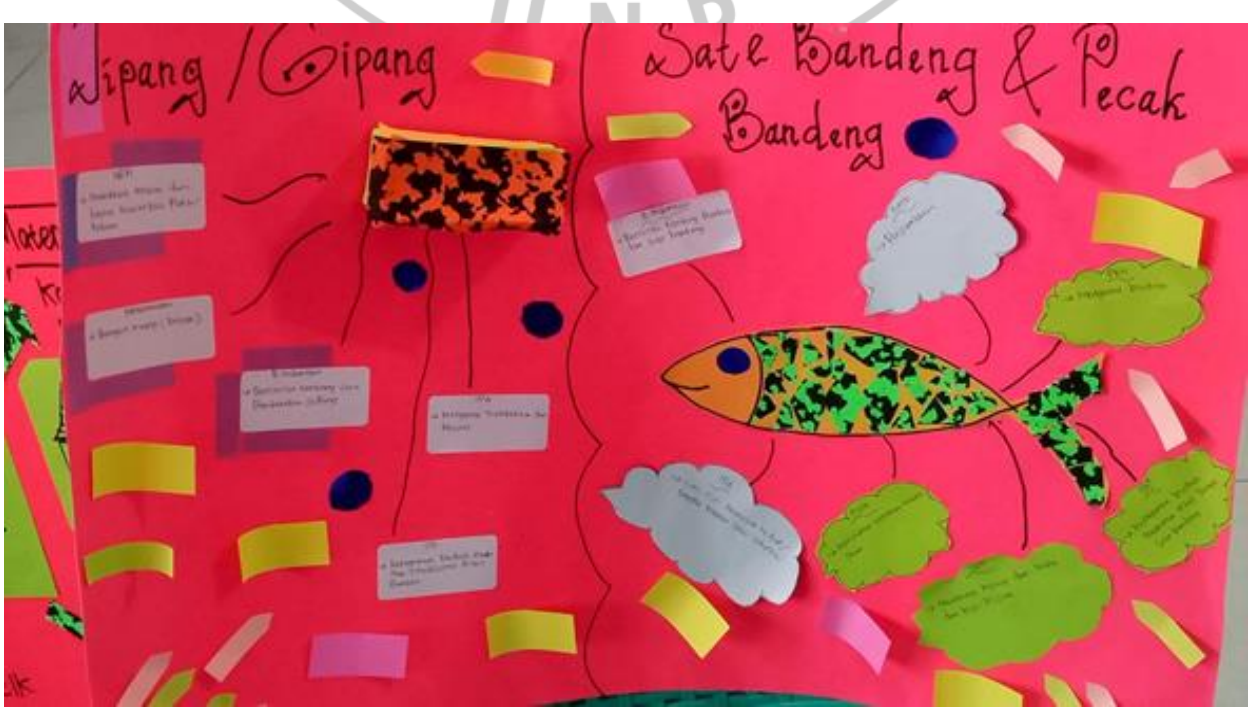

Gambar 3. Keterkaitan konsep dengan Gipang dan Sate Bandeng 
Penggunaan pengetahuan budaya, pengalaman sebelumnya, untuk membuat pembelajaran lebih relevan dan efektif untuk mengkonstruksi pengetahuan yang baru. Hal ini membuat guru nyaman dan merasa terlibat dalam proses pembelajaran yang dilakukan. Guru belajar untuk mengenal budayanya dan berinteraksi dengan orang lain, tanpa mengabaikan pemahaman konsep yang akan disampaikan (Gay, G., 2000).

\subsection{Berpikir Kritis}

Berpikir kritis merupakan suatu pola pikir dengan menggunakan berbagai alasan, seperti alasan induktif atau deduktif dalam berbagai situasi. Berpikir kritis juga dapat diartikan sebagai cara berpikir sistematis dengan membuat keputusan dan kemampuan untuk mengatasi masalah (Trilling, B. \& Fadel., 2009). Pemikiran kritis mencakup keterampilan komponen dalam menganalisis argumen, membuat kesimpulan dengan penalaran induktif atau deduktif, menilai atau mengevaluasi, dan membuat keputusan atau memecahkan masalah. Pemikiran kritis melibatkan keterampilan dan disposisi kognitif. Sifat-sifat ini, yang dapat dilihat sebagai sikap atau kebiasaan pikiran yang mencakup keterbukaan pikiran, rasa ingin tahu, fleksibilitas, kecenderungan untuk mencari alasan, keinginan untuk mendapatkan informasi yang baik, rasa hormat, dan kemauan untuk melihat sesuatu dari berbagai sudut pandang. "Kegiatan sangat menarik dapat menstimulasi kreativitas dan berpikir kritis, khususnya dalam eksplorasi budaya dalam pembelajaran" (Refleksi guru SDIT 1).

Guru dapat mengembangkan berpikir kritisnya melalui proses pencarian perbedaan perspektif budaya yang dapat menantang pengetahuan (Rahmawati, Y., \& Ridwan, A., 2019). Tahap ini dalam CRTT sejalan dengan prinsip dari Social Justice, dimana guru didorong untuk bertanya dan ditantang untuk lebih kritis (Hernandez, C.M., Morales, A.R. \& Shroyer, M.G., 2013). Pada workshop ini, guru dituntut aktif untuk berpikir secara kritis mengenai budaya serta konsep yang akan diajarkan.

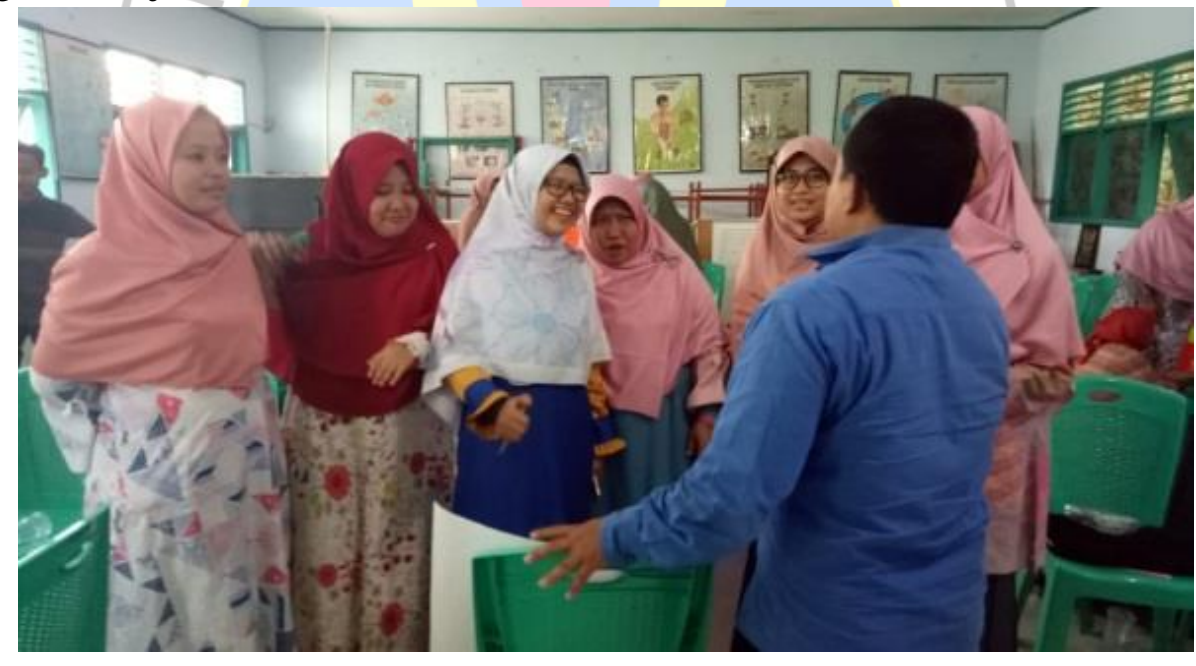

Gambar 4. Guru bertanya terkait konsep dan budaya

Kegiatan workshop yang dilaksanakan cukup aktif, dimana guru bertanya mengenai keterkaitan materi yang disampaikan dengan budaya Banten. workshop ini dapat memotivasi guru pada peranannya sebagai fasilitator dalam pembelajaran dengan memupuk rasa ingin tahu dan berpikir kritis serta mencintai kebudayaannya.

\subsection{Bekerja sama}

Bekerja sama memungkinkan interaksi dengan orang lain dan bertanggung jawab atas tindakan mereka, termasuk belajar dan menghargai kemampuan serta kontribusi teman sebayanya. Tahap kerjasama adalah dimana guru bekerja di dalam satu grup untuk mendiskusikan konsep budaya dan perspektif budaya (Rahmawati, Y., \& Ridwan, A, 2019). CRTT memberikan 
kesempatan kepada guru untuk mencapai tujuan mereka melalui pembelajaran yang dapat meningkatkan kemampuan interpersonal diantaranya berbagi terhadap sesama dan saling menghargai di dalam perbedaan budaya (Gay, G., 2000). "Saya senang kerja kelompok antara guru dalam mata pelajaran yang berbeda, ide-ide berbeda dalam melihat satu aplikasi budaya yang sama (Wawancara guru SDIT 2).

Pada tahap kolaborasi ini, guru cenderung saling belajar dan memberikan masukan satu sama lain. Pada proses kerja kelompok, terdapat pembagian tugas dan penerimaan tanggung jawab di antara anggota kelompok terhadap hasil kerja kelompok tersebut (Laal, M., \& Seyed M. G., 2011).

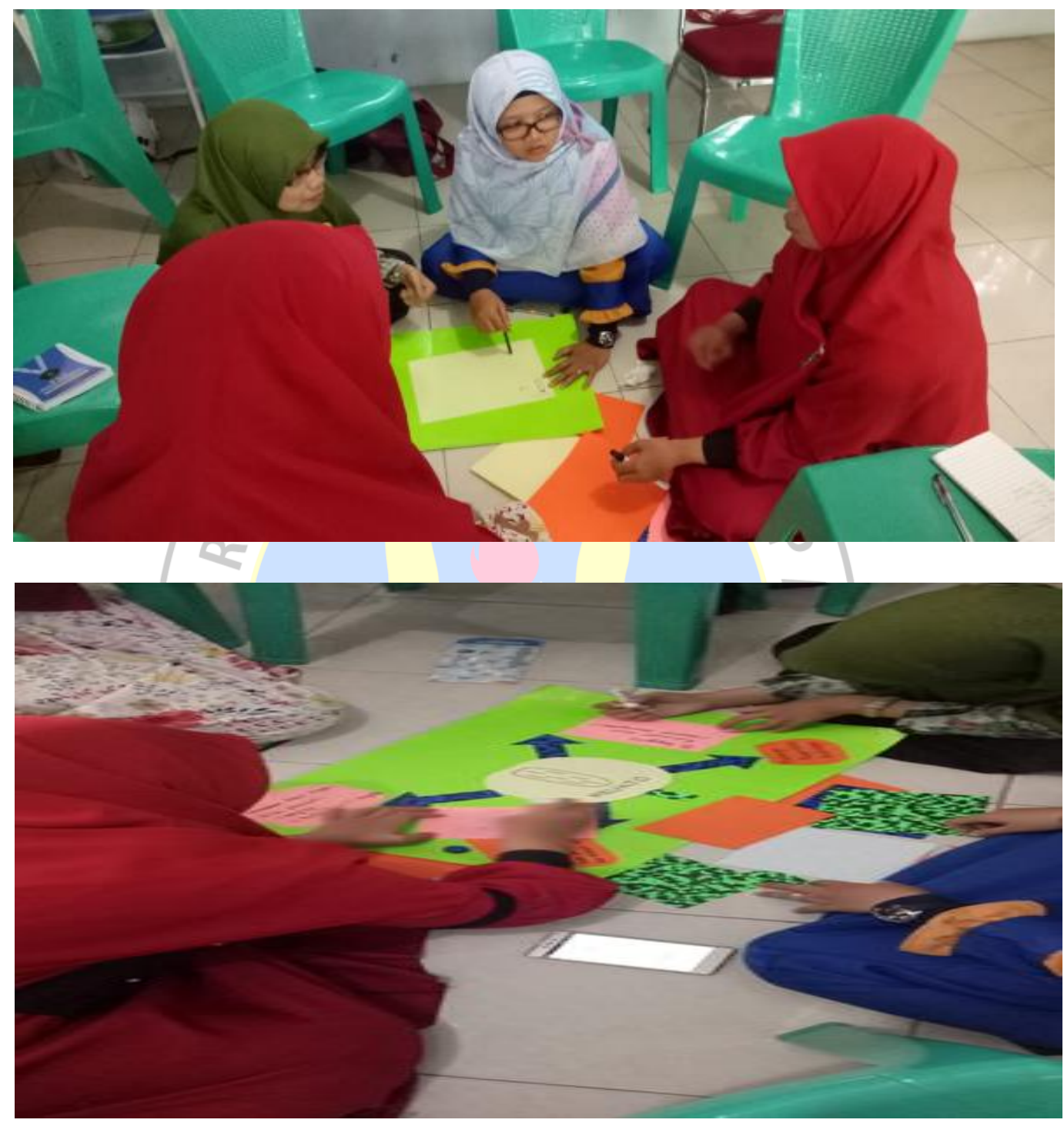

Gambar 5. Guru bekerja sama dalam mengintegrasikan ide

Workshop ini mendorong guru antar mata pelajaran untuk bekerja secara berkelompok yang berdampak terhadap kemampuan meningtegrasikan pemikiran berbeda dari setiap guru mata pelajaran.

\subsection{Rasa Ingin Tahu}

Workshop pengembangan kompetensi guru dalam menerapkan model pembelajaran dengan pendekatan CRTT merupakan pembelajaran yang baru bagi guru, sehingga mendorong keingintahuan guru. Rasa ingin tahu merupakan keinginan untuk menyelidiki dan memahami suatu fenomena atau pernyataan (Samani, M \& Hariyanto, 2012). Workshop yang dilaksanakan membuat 
guru antusias karena variasi penggunaan metode yang disesuaikan dengan karakteristik peserta didik, serta kaitannya dengan budaya peserta didik. Workshop yang dilaksanakan membantu guru dalam menciptakan pembelajaran yang bermakna, guru merupakan Facilitating of Content Knowledge yang membantu peserta didik untuk mendapatkan pembelajaran berdasarkan apa yang dibutuhkan (Hernandez, C.M., Morales, A.R. \& Shroyer, M.G., 2013).

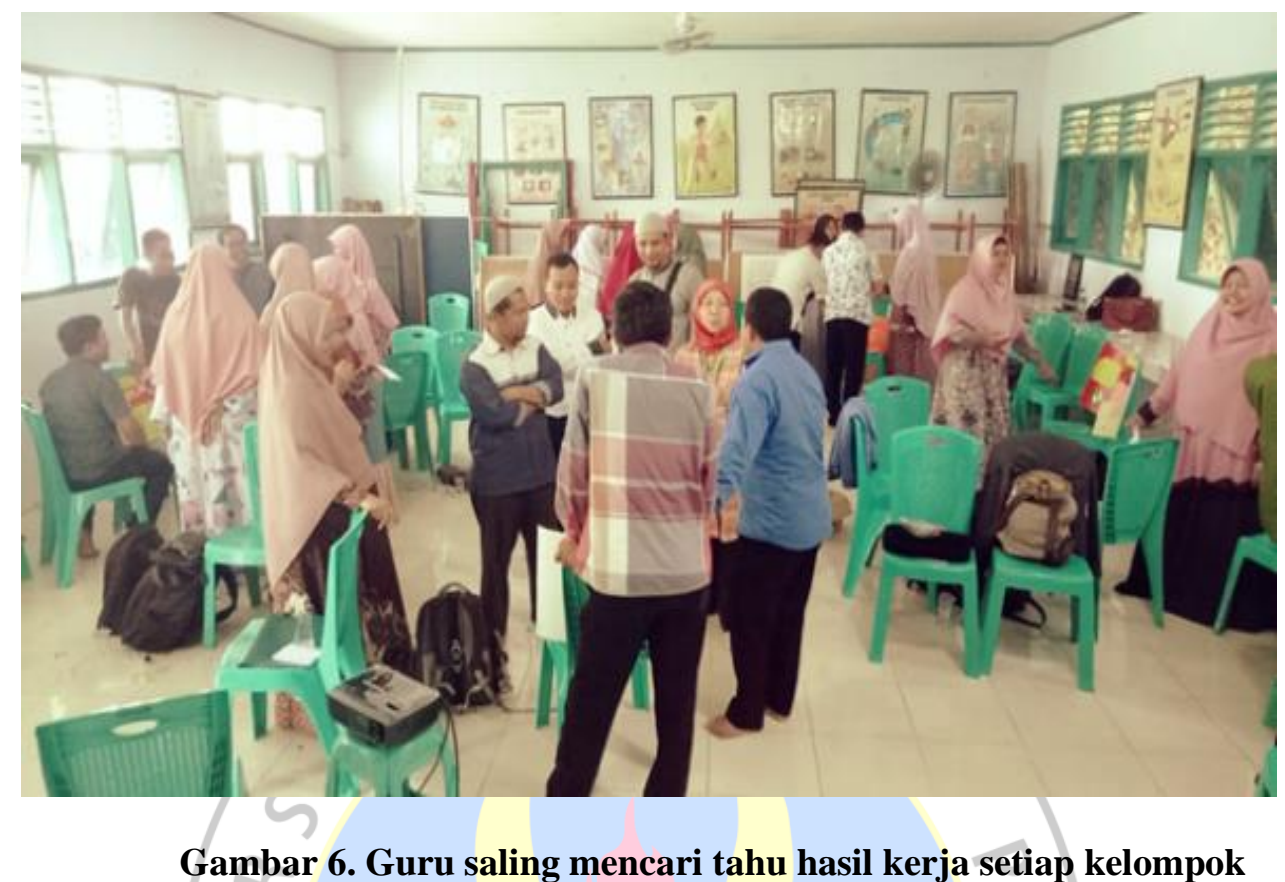

Rasa ingin tahu terlihat dari antusias guru memberikan pertanyaan. Rasa ingin tahu dapat meningkatkan intensitas belajar dan memori, dengan adanya rasa ingin tahu akan mengkonseptualisasikan keingintahuan dan motivasi, mempelajari hal baru, kompleksitas, dan informasi lainnya, (Ondeyer, et all., 2016).

Pada akhirnya guru menyadari bahwa pembelajaran berbasis budaya CRTT dapat menunjang terbentuknya soft skills guru dan sesuai dengan pengembangan karakter/pada kurikulum 2013. Pembelajaran dengan pendekatan budaya dapat membantu guru dalam memahami budayanya dan mengintegrasikan dalam pembelajaran serta budaya orang lain yang berdampak pada ketertarikan guru terhadap proses pembelajaran dalam sudut pandang yang berbeda. Berdasarkan hasil analisis data secara keseluruhan, terutama pada refleksi guru, pembelajaran ini memiliki tantangan dalam penerapannya meliputi integrasi budaya dalam konsep, perubahan paradigm peserta didik dan guru, serta keterbatasan waktu. Namun pendekatan ini dapat dikembangkan dalam berbagai topik dalam pembelajaran

\section{Kesimpulan}

Pembelajaran berbasis budaya merupakan inovasi pembelajaran yang dapat diintegrasikan oleh guru dalam berbagai mata pelajaran. Pada pelatihan ini guru memahami model pembelajaran melalui pendekatan CRTT dengan 5 tahapan: self identification (identitas diri), cultural understanding (pemahaman budaya), collaboration (kolaborasi), critical reflections (berpikir refleksi kritis), transformative construction (konstruksi transformative). Pada pelatihan ini difokuskan pada persiapan tahapan cultural understanding, dengan mengintegrasikan budaya pada mata pelajaran yang berbeda. Pelatihan dilakukan ini dilakukan dengan metode workshop dan kerja kelompok terkait dengan latar belakang budaya dan kehidupan sehari-hari. Model pembelajaran CRTT mampu mengembangkan kreativitas integrasi konten budaya, berpikir kritis, bekerjasama, dan rasa ingin tahu. Hasil workshop menunjukkan bahwa kegiatan menstimulasi kreativitas guru dalam mengintegrasikan budaya dengan konsep berbagai mata pelajaran, namun guru juga 
menyadari model pembelajaran ini menghadapi tantangan dalam keterbatasan waktu, serta perubahan paradigma peserta didik dan guru. Pendekatan CRTT selanjutnya dapat dikembangkan dalam budaya dan mata pelajaran lain, serta mengkaji lebih dalam dampaknya terhadap proses dan hasil belajar peserta didik, dan kompetensi guru.

\section{Daftar Pustaka}

Aikenhead, G. (2000). Renegotiating the culture of school science. In J. L. R. Millar, \& J. Osborne (Ed.), Improving Science Education: The Contribution of Research (pp.245-264). Birmingham: Open University Press.

Arifah. (2014). Kurikulum 2013 Implementasikan Grand Design Kebudayaan. http://kebudayaan.kemdikbud.go.id/ditkt/2014/07/07/kurikulum-2013-implementasikangrand-design-bidang-kebudayaan.

Arthur, J. (2009). Traditional approaches to character education. In L.P. Nucci \& D. Narvaez, Handbook of Moral and Character Education. UK: Routledge.

Arthur, J. \& Wilson, K. (2010). In new research directions in character and values education in the UK. T. Lovat et al. (eds.), International Research Handbook on Values Education and Student Wellbeing. UK: Springer.

Badan Pusat Statistik. (2010). Hasil Sensus Penduduk 2010. https;//sp2010.bps.go.id.

Cartledge, G. \& Kourea, L. (2008). Culturally Responsive Classrooms for Culturally Diverse Students With and at Risk for Disabilities. Exceptional Children, 74(1), 351-371.

Chang, F. \& Muñoz, M.A. (2006). School personnel educating the whole child: Impact of character education on teachers' self-assessment and student development. Journal Personal Evaluation Education, 19(1), 35-49.

Daniel, S. (2007). Profesionalisme Melalui Sertifikasi sebagai Upaya Peningkatan Mutu, Kompetensi, Jumlah dan Kesejahteraan Guru/Dosen. Makalah. Universitas Airlangga.

Gay, G. (2000). Culturally Responsive Teaching: Theory, Practice, and Research. New York: Teachers College Press.

Hassan, S. (2007). Konfigurasi Identitas Nasional, Nasionalisme, dalam Era Globalisasi Suatu Harapan dan Tantangan. Surakarta: Universitas Sebelas Maret.

Hutcheon, P.D. (1999). Building character and culture. Wesport Connecticut: Praeger.

Laal, M., \& Seyed M. G. (2011). Benefits of Collaborative Learning. Procedia, Social and Behavioral Sciences, 31(1), 486-490.

Ladson-Billings, G. (1995). Toward Culturally Relevant Pedagogy. American Educational Research Journal, 32(3), 465-491.

Mubah. A.S. (2011). Strategi Meningkatkan Daya Tahan Budaya Lokal Dalam Menghadapi Arus Globalisasi. Departemen Hubungan Internasional FISIP, 24(4), 302-308.

Nieto, S. (2016). Re-Imagining Multicultural Education: New Visions, New Possibilities. Multicultural Education Review, 9(1), 1-10.

Nisa, A, Sudarmin, dan Samini. (2015). Efektivitas Penggunaan Modul Terintegrasi Etnosains dalam Pembelajaran Berbasis Masalah untuk Meningkatkan Literasi Sains Peserta Didik. Unnes Science Education Journal, 4(3), 1049-1056

Ondeyer, et all. (2016). Instrinsic Motivation, Curiosity, and Learning: Theory and Applications in Educational Technologies. Science Direct, 229(1), 257-284.

Otasevic, K. (2013). Cultural diversity and cultural identity in globalization. http://www.wseas.us/e-library/conferences/2013/Chania/AEBDb/AEBDb-21.pdf.

Peraturan Menteri Pendidikan dan Kebudayaan Republik Indonesia Nomor 103 Tahun 2013 tentang Pembelajaran pada Pendidikan Dasar dan Pendidikan Menengah.

Permenpan dan RB Nomor 16 Tahun 2009 tentang Jabatan Fungsional Guru dan Angka Kreditnya

Rahmawati, Y. \& Taylor, P.C. (2015). Moments of Critical Realisation and Appreciation: A Transformative Chemistry Teacher Reflects. Reflective Practice, 16(1), 31 - 42.

Rahmawati, Y., Nurbaity, \& Marheni (2014). Pembelajaran Dilemmas Stories dalam Upaya Pengintegrasian Nilai-Nilai Karakter dan Budaya Serta Pengembangan Soft Skills dalam Pembelajaran Kimia. Laporan Penelitian. Universitas Negeri Jakarta 
Rahmawati, Y. \& Taylor, P.C. (2017). The Fish Becomes Aware of The Water in Which It Swims": Revealing The Power of Culture In Shaping Teaching Identity. Culture Studies Science Education, https://doi.org/10.1007/s11422-016- 9801-1.

Rahmawati, Y., \& Ridwan, A. (2019). Empowering Students' Chemistry Learning: The Integration Of Ethnochemistry in Culturally Responsive Teaching. Chemistry: Bulgarian Journal of Science Education, 6(6), 813-830.

Ridwan, Rahmawati, Hadinugrahaningsih, \& Nurbaity. (2017). Integration of A Socio-Critical and Problem Oriented Approach in Chemistry Learning for Students Soft Skills Development. MIER Journal of Educational Studies Trends and Practices, 7(1), 33-41.

Sarwanto, \& Budiharti, R. (2013). Identifikasi Sains Asli (Indigenous Science) Sistem Pranata Mangsa Melalui Kajian Etnosains. Artikel Seminar Nasional. Universitas Negeri Solo.

Semali, L. (2013). The Ispaces Framework to Restructure Culturally Responsive Secondary Science Curriculum in Tanzania. Journals of University of Alberta libraries, 8(2), 32-46.

Samani, M \& Hariyanto. (2012). Pendidikan Karakter: Konsep dan Model. Bandung: Remaja Rosdakarya

Sudarmin , Febu, R., Nuswowati , M., \& Sumarni, W. (2017). Development Ethnoscience Approach in The Module Theme Substance Additives to Improve The Cognitive Learning Outcome and Student's Entrepreneurship. The 3rd International Conference on Mathematics, Science and Education 2016 IOP Publishing IOP Conf. Series: Journal of Physics: Conf, 824(20).

Trilling, B dan Fadel. (2009). 21st Century Skills: Learning for Life in Our Times. UK: John Wiley and Sons.

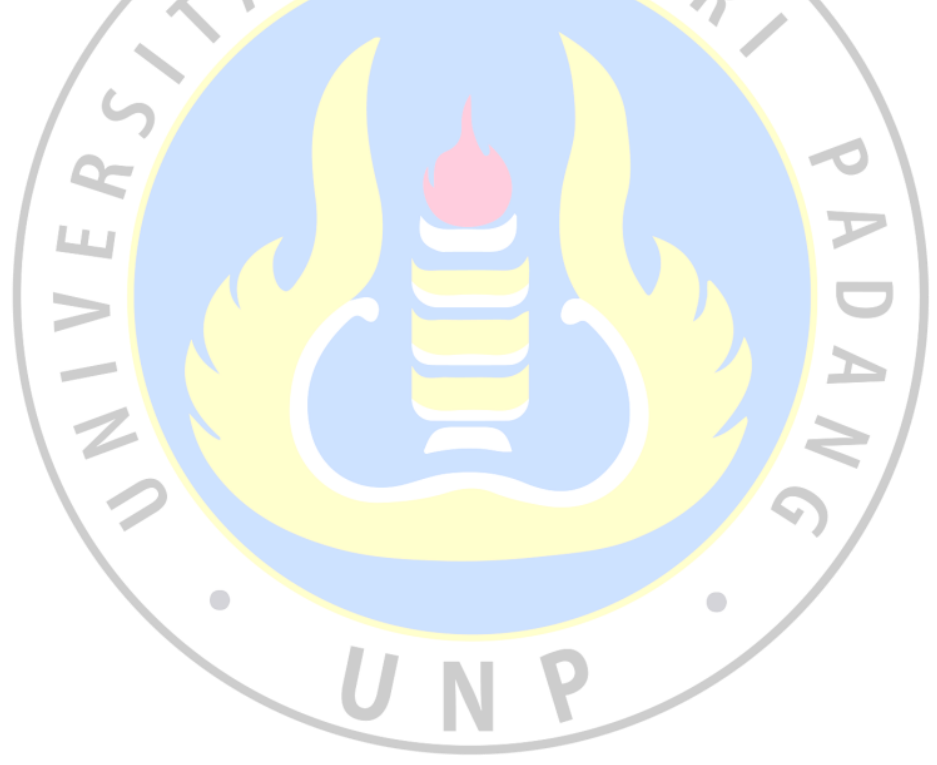

